\title{
La democracia del Nunca más y el movimiento obrero. La ocupación obrera de la planta Ford de General Pacheco en 1985
}

\author{
Leandro Molinaro \\ UBA
}

El presente artículo plantea un acercamiento a una de las problemáticas relacionadas con las luchas entre capital y trabajo en los primeros años de la transición democrática. En particular, nos enfocamos en la ocupación obrera de la planta Ford de General Pacheco -ocurrida entre el 26 de junio y el 14 de julio de 1985- debido a que fue uno de los conflictos más relevante de los que surgieron como respuesta al Plan Austral instrumentado por el gobierno alfonsinista. Su importancia se encuentra relacionada con su masividad y la trascendencia pública que tomó. Si bien la historiografía abordó este conflicto (Hernández, 1985; García Allegrone, Partenio y Álvarez, 2003; Giniger, Guevara, Hernández y Rivero, 2010), la especificidad de este trabajo se encuentra en el intento de relacionarlo con el proceso de consolidación de un relato legitimador del orden democrático impulsado, principalmente, desde el Estado. Entre otras cuestiones, este discurso incluía la "demonización" de las estrategias y prácticas gremiales llevadas a cabo para resistir la ofensiva de la burguesía iniciada a mediados de la década de 1970 .

\section{El país del Nunca Más}

Situar temporalmente el conflicto analizado en este trabajo implica realizar algunas observaciones sobre la situación política, social y económica de los primeros años de la transición democrática. Tras la guerra de Malvinas en 1982 la dictadura militar entró en descomposición. Fueron convocadas elecciones presidenciales para octubre de 1983, en las que triunfó el candidato de la Unión Cívica Radical (UCR), Raúl Alfonsín. Fue la primera vez que el Partido Justicialista (PJ) salió derrotado en una elección de este tipo sin proscripciones. Además significó el final de un ciclo de más de cincuenta años de alternancia entre gobiernos militares y constitucionales (muchos de estos últimos fraudulentos o restringidos).

En una coyuntura marcada por las movilizaciones sociales para esclarecer las violaciones de derechos humanos, el gobierno decidió impulsar una particular versión de los años 70 para consolidar su concepción de la 
democracia. En este sentido, el Poder Ejecutivo y otras instituciones estatales llevaron a cabo diversas medidas, entre las cuales se destacaron la sanción de los decretos 157 y 158, la creación e investigación de la Comisión Nacional sobre la Desaparición de Personas (CONADEP), que derivaría en el informe conocido como Nunca más en septiembre de 1984, y el juicio a los ex comandantes de las tres primeras Juntas Militares llevado a cabo por la Cámara Federal entre abril y diciembre de 1985 (Crenzel, 2008; Novaro, 2009). El juzgamiento a los militares transcurrió en un clima de fuerte presión de las Fuerzas Armadas y coincidió con el desarrollo del conflicto obrero analizado en este trabajo. El fallo de este juicio fue inédito e histórico ya que, entre otras cuestiones, sentenció a cadena perpetua a dos de los ex comandantes, Jorge Videla y Emilio Massera, y estableció la existencia de un plan sistemático de terrorismo de Estado.

Estas acciones fueron realizadas desde la lógica de la "teoría de los dos demonios". Esta última circunscribía las responsabilidades de los conflictos sociales de los 70 en dos "demonios" que atacaron a una sociedad "inocente", ocultaba la existencia y las características de la lucha de clases previa al golpe cívico-militar de 1976 y, por ende, las causas de la masacre llevada a cabo por el Estado.

Otro marco de conflictividad en este período estuvo relacionado con la crisis económica heredada de la última dictadura militar, una cuestión de difícil solución para el alfonsinismo. El fracaso de la gestión de Bernardo Grinspun en el Ministerio de Economía durante 1984 -en la cual hubo una tasa de inflación anual de más del 600\%-llevó a Alfonsín a trazar un cambio en el rumbo económico. Para ello nombró a Juan Sourrouille en la cartera económica a comienzos de 1985. La intención del gobierno era solucionar los problemas del déficit fiscal, la inflación y el endeudamiento (Ortiz y Schorr, 2006: 297; Aspiazu, Basualdo y Khavisse; 2004). En este sentido, Sourrouille diseñó el denominado Plan Austral, que consistió en la puesta en marcha de medidas estabilizadoras heterodoxas para controlar la inflación y que fue parte de un acuerdo con el Fondo Monetario Internacional (FMI) y los sectores más concentrados de la burguesía. El plan económico entró en vigencia el 14 de junio de 1985 y tuvo, en lo inmediato, consecuencias recesivas en distintas ramas industriales. Como ejemplo podemos señalar que más de un tercio de los conflictos en el sector privado durante ese año tuvieron como causa la inestabilidad laboral y la pérdida de fuentes de trabajo (Bonanotte y Zeller, 1994: 83).

El contexto de crisis económica y la lógica de construcción de poder político configuraron una nueva relación entre el Estado y el movimiento obrero. A comienzos de su mandato, el alfonsinismo había enviado al parlamento un proyecto de ley de "Reordenamiento Sindical" con el cual se intentaba "democratizar" -y al mismo tiempo debilitar-al movimiento obrero. El proyecto no pudo convertirse en ley (en la Cámara del Senado fue rechazada por dos 
votos) y el gobierno pasó a una estrategia negociadora con los sindicatos en manos de agrupaciones peronistas.

$\mathrm{Al}$ interior de la Confederación General del Trabajo (CGT), reunificada desde enero de 1984, predominaban cuatro nucleamientos políticos: las 62 Organizaciones, la Comisión Nacional de los 25, la Comisión de Gestión y Trabajo y la Comisión de los $20 .{ }^{1} \mathrm{El}$ más poderoso de éstos era las 62 Organizaciones, liderada por el metalúrgico Lorenzo Miguel, representante del sector ortodoxo del peronismo sindical. La Comisión Nacional de los 25, a la que pertenecía el Sindicato de Mecánicos y Afines del Transporte Automotor (SMATA), era la agrupación opositora al miguelismo y se presentaba como la continuadora de "las corrientes combativas del movimiento obrero comprometidas con la restauración democrática” (Belardinelli, 1994: 117). En términos partidarios, Lorenzo Miguel estaba alineado con la cúpula del PJ derrotada en las elecciones presidenciales de 1983, que mantenía la conducción del justicialismo, mientras que la Comisión de los 25 apoyaba al denominado "peronismo renovador", línea interna que buscaba tomar las riendas de un partido en crisis.

No obstante, estos nucleamientos no mantenían un control total del movimiento obrero. Según datos de la época, la cúpula peronista, en todas sus variantes, controlaba el 90 por ciento de las conducciones nacionales de los gremios, el 80 por ciento de las conducciones de seccionales y el 70 por ciento de las comisiones internas. El 30 por ciento de las organizaciones de base estaban en manos de agrupaciones de izquierda fuera del control de la dirigencia sindical. Estas agrupaciones eran el Movimiento al Socialismo (MAS), Partido Obrero (PO), Partido Comunista Revolucionario (PCR) cuya entidad legal en ese momento era Partido del Trabajo y el Pueblo (PTP), Partido Comunista (PC) y sectores sindicales del peronismo que no respondían a ninguno de estos nucleamientos antes mencionados. ${ }^{2}$

La CGT se opuso a la aplicación del Plan Austral e impulsó dos huelgas generales que movilizaron, en ambos casos, más de 120.000 personas a Plaza de Mayo. Una antes de la aplicación del plan, el 23 de mayo, y otra el 29 de agosto con el fin de que el gobierno abandonase definitivamente "la política recesiva impuesta por los centros de poder financiero transnacional, y se adopte la de crecimiento nacional con justicia social" (Novaro, 2009: 141).

1. La CGT estaba codirigida por cuatro gremialistas que representaban diferentes expresiones políticas del sindicalismo: Saúl Ubaldini (del sindicato cervecero, miembro de la Comisión Nacional de los 25 y anterior líder de la CGT-Brasil), Jorge Triaca (del sindicato del plástico, líder de la Comisión de Gestión y Trabajo y anterior conductor de la CGT-Azopardo), Ramón Baldassini (del sindicato de correo) y Osvaldo Borda (del sindicato del caucho).

2. Todos los datos de este párrafo fueron tomados de Tabaré Areas, "El plan amenazado", Somos, núm. 460, 12/7/1985, p. 8; Joaquín Morales Solá, "La ocupación, otros interlocutores", "Panorama Político", Clarin, 14/7/1985, p. 16. 
Además, el movimiento obrero llevó a cabo medidas de lucha que incluyeron, principalmente, 367 denuncias públicas del conflicto, 60 movilizaciones, 41 paros y 33 ocupaciones de fábricas, entre ellas la planta de Ford ubicada en la localidad de General Pacheco en la Zona Norte del Gran Buenos Aires. ${ }^{3}$ En los dos meses siguientes a la puesta en marcha del Plan Austral, miles de trabajadores llevaron a cabo acciones de protesta. Muchas de estas medidas fueron impulsadas por organizaciones de base dirigidas por agrupaciones de izquierda que se configuraron como uno de los actores más combativos contra la avanzada de los sectores concentrados de la burguesía y el gobierno de Alfonsín.

\section{La ocupación de la planta Ford}

La industria automotriz venía efectuando una reducción del personal a partir de los cambios en el sistema de producción a nivel internacional y por la situación de recesión y estancamiento que existía en el país desde la década de 1970. En particular, la empresa transnacional Ford había despedido 6.000 trabajadores durante la última dictadura militar. ${ }^{4}$ Con la reapertura democrática, los obreros de esta empresa pudieron reconstituir la comisión interna y el cuerpo de delegados disueltos a partir de la represión estatal de los años 70. Tras la aplicación del Plan Austral, la empresa continuó con su política de reducción del personal. El hecho que desencadenó la decisión mediante asamblea de tomar la planta de General Pacheco por parte de más de 3.800 obreros (sobre un total de aproximadamente 4.500) fue el despido de 33 trabajadores. Esto significaba un incumplimiento del acta-acuerdo firmada el 17 de mayo de ese año por la comisión interna y la empresa. En este documento Ford se había comprometido a no realizar despidos ni suspensiones hasta el 31 de julio. Ante esta situación, la empresa mantuvo su posición. Suspendió la producción y ordenó a los capataces que se llevaran

3. Datos obtenidos de "Estadísticas del Australazo", Latinoamérica. En su realidad politica, social y cultural, $\mathrm{N}^{\circ} 18$, septiembre de 1985, p. 5. De la información relevada en distintas publicaciones pudimos observar que durante este período también fueron tomados los siguientes establecimientos: metalúrgica Volcán, frigorífico Tres Cruces, Banco Italia y Banco Juncal (Capital Federal); Banco de la Empresa Cooperativo y textil Tejidos Universal (Mar del Plata); cementera "Juan Minetti" y bodegas Furlotti (Mendoza); baterías "Buscema" (Paraná), frigorífico "Formosa" (Formosa), Banco Regional Cooperativo (Córdoba), cristalería La esperanza (Bernal), plásticos Viplastic (Burzaco), neumáticos Firestone (Llavallol), metalúrgica Carrasco, Acero Bragado y cristalería Cuyo (Rosario).

4. Datos tomados de "Que se juega en la lucha de Ford", Qué pasa, núm. 228, $17 / 7 / 1985$, p. 4. Cabe agregar que la empresa Ford fue señalada como cómplice de la represión estatal y paraestatal de los años 70 con la colaboración en la entrega de listas de activistas de su compañía a la Triple A y el Ejército (Löbbe, 2006). 
las herramientas de las diferentes secciones con el fin de paralizar la producción. En este sentido, también estableció que el personal administrativo se retirara de la fábrica. Aplicaba, así, un lock out empresarial.

Desde un principio, el gobierno condenó el accionar de los trabajadores. Si bien el Ministro de Trabajo, Hugo Barrionuevo, intimó a la empresa a revisar la medida tomada el 25 de junio, declaró ilegal la ocupación e instó a la comisión interna a desalojar la planta. ${ }^{5}$ Además, el gobierno se negó a declarar la conciliación obligatoria retrotrayendo la situación al momento previo al conflicto. Los obreros mantuvieron su posición argumentando que con la toma defendían sus puestos de trabajo y que era la empresa la responsable de esa situación provocada con el lock out. La compañía se negó a aceptar esta intimación argumentando que la ocupación atacaba la propiedad privada. Además, justificaba los despidos en motivos disciplinarios -ausentismo elevado crónico y falta de contracción en las tareas- que no se encontraban incluidos dentro del acta-acuerdo del 17 de mayo.

La ocupación fue motorizada por la comisión interna y el cuerpo de delegados cuyos miembros pertenecían en su mayoría a la Lista Naranja. Esta agrupación estaba compuesta principalmente por militantes del PCR-PTP y, en menor medida, del MAS y el PO que habían realizado un trabajo clandestino durante los últimos años de la dictadura y se habían consolidado en los cuerpos de delegados y en la comisión interna durante la normalización de 1984. En este sentido, el coordinador de la comisión interna y principal dirigente de la ocupación era Miguel Delfini, militante el PCR-PTP. También había trabajadores que respondían al PC y al sector del peronismo bonaerense al que pertenecían Herminio Iglesias y el diputado Norberto Imbelloni.

La medida fue rechazada y criticada por la conducción central del SMATA, cuyo máximo dirigente era el peronista José Rodríguez, que tenía el control del sindicato a nivel nacional pero poca influencia dentro de Ford. ${ }^{6}$ Institucionalmente, la CGT no dio muestras de apoyo a la ocupación debido al peso que tenía la cúpula del SMATA en su interior.

Los obreros de Ford recibieron adhesiones y muestras de solidaridad de políticos de diversas corrientes (principalmente dirigentes de los partidos de izquierda ya citados, el justicialismo y el Partido Intransigente), centros

5. "Recíproca contumacia”, Crónica (1era. edición), 29/6/1985, p. 2.

6. En octubre de 1984 se realizaron elecciones en el gremio automotriz en las que triunfó a nivel nacional la Lista Verde de José Rodríguez con el 50\% de votos, seguida por la Lista Azul y Blanca, liderada por el peronista ortodoxo y trabajador de Ford, Jorge Castro, con el 43\% y la Lista Naranja con el 7\%. En la Ford los resultados fueron diferentes. En la planta de Pacheco, la lista más votada fue la Azul y Blanca (52\%), seguida por la Lista Naranja (40\%) y la Lista Verde de Rodríguez en último lugar (7,9\%) (Santella, 2008: 222). Cabe aclarar que Castro fue uno de los 850 obreros que aceptaron el retiro voluntario propuesto por Ford dos meses antes de la ocupación. Esto le dio un peso mayor a los miembros de la Lista Naranja en la empresa. 
de estudiantes de escuelas secundarias y universitarios, Madres de Plaza de Mayo y miembros de otras organizaciones de derechos humanos (como Adolfo Pérez Esquivel), comisiones internas de otras empresas y artistas (muchos de ellos participaron de un festival en solidaridad hacia los trabajadores de Ford realizado el 14 de julio). ${ }^{7}$ En su mayoría estos apoyos tuvieron un carácter testimonial y simbólico. No se conformó una fuerza social amplia que articulara las demandas particulares de los trabajadores.

Desde el comienzo del conflicto, la toma tuvo una organización rigurosa. La gran mayoría de los operarios permanecieron en la fábrica solidarizándose con sus compañeros despedidos. Las decisiones eran tomadas por las asambleas de cada sección y, luego, en asamblea general. Dado el gran tamaño del complejo (160 hectáreas) rodearon las puertas de la fábrica con autos para tener un control estricto de las entradas y salidas. Para albergar a la gran cantidad de trabajadores que permanecían en el establecimiento improvisaron dormitorios en las fábricas y se distribuían alimentos recolectados a través de donaciones. También puede observarse una disciplina aceitada que incluía la prohibición de bebidas alcohólicas y el establecimiento de turnos rotativos de guardia de dos horas. Los familiares tenían horario de visita de 9 a 19 horas. Planificaban actividades recreativas (voley, ping pong, juego de naipes y ajedrez) para ocupar el tiempo libre. Incluso, el 9 de julio llevaron a cabo un acto por la celebración del día de la independencia. Además, la comisión interna se encargaba de redactar comunicados de prensa y distribuir piquetes para controlar cada espacio del complejo. ${ }^{8}$ En los días siguientes a la toma se constituyó una Comisión de Familiares, formada, principalmente, por las compañeras y madres de los trabajadores que realizaron una huelga de hambre durante 48 horas (entre el 3 y el 5 de julio) y lograron entrevistarse con el líder sindical Saúl Ubaldini. ${ }^{9}$

La organización planificada de la toma también pudo observarse en los momentos previos al desalojo. Para resistir una posible incursión de la policía dentro de la fábrica, los trabajadores se habían parapetado detrás de automóviles y la comisión interna utilizaba los parlantes del establecimiento para pedirle a los obreros que no provocaran a los agentes uniformados, ni utilizasen objetos contundentes contra ellos, y que sólo recurriesen a los extinguidores para apagar bombas de gas lacrimógeno.

Para contrarrestar las acusaciones de la empresa sobre el deterioro de la maquinaria, los trabajadores decidieron poner la planta en funcionamiento

7. Véase: "Adhesiones", Hoy, servir al pueblo, N $^{\circ} 76,3 / 7 / 1985$, pp. 6-7; "Adhesiones de otros sectores; documento", Crónica (1era. edición), p. 2.

8. Datos tomados de: "Obreros atrincherados en la planta de Ford", Crónica (5ta. edición), pp. 10-11; Luis Castillejos, "Motores al rojo vivo", Somos, № 459, 5/7/ 1985,

p. 13; Tabaré Areas, "El plan amenazado", op. cit., p. 7.

9. "La huelga de hambre", Hoy, servir al pueblo, No 77, 10/7/1985, p. 5. 
entre el jueves 11 y el viernes 12 de julio. Según el semanario del PCR-PTP, participaron en las actividades laborales tres mil obreros mientras que otros mil permanecieron en los puestos de guardia. Se llevaron a cabo tareas en la planta de camiones, motores, estampados y montajes. Al poner en producción la fábrica, buscaban demostrar públicamente que las instalaciones se encontraban en perfectas condiciones. Incluso, algunos trabajadores declararon públicamente que el control obrero de la producción era más seguro y organizado, ya que en los años previos la empresa había despedido una gran cantidad de controladores y faltaban insumos como guantes y zapatos de goma. ${ }^{10}$

Cabe señalar que mientras se desarrollaba la ocupación de la planta existieron denuncias sobre persecuciones, amenazas e intimidaciones a familiares de trabajadores en sus hogares por bandas parapoliciales. Este clima represivo nos muestra que el Estado y la compañía no sólo se valían de medios legales y declaraciones públicas para amedrentar a los obreros que permanecían en la planta. ${ }^{11}$

La presión en aumento de la empresa, sumada a las acciones de persecución de la comisión interna y el cuerpo de delegados desde el Poder Judicial y el gobierno de Alfonsín y la falta de apoyo del SMATA y la CGT fueron los factores principales que desencadenaron el desalojo de la fábrica en la madrugada del 14 de julio. Tras dieciocho días de ocupación, la planta fue rodeada por un dispositivo policial que contó con 2.000 efectivos armados, 200 patrulleros, carros de asalto, tres helicópteros de combate, policía motorizada y montada, perros, reflectores y tanquetas. Ante esta situación amenazante, los obreros reunidos en asamblea decidieron resistir, aunque luego de un breve enfrentamiento, optaron por que la comisión interna negociase un desalojo pacífico con el juez federal Carlos Valdez, encargado del operativo policial.

En los días posteriores al desalojo, la empresa tomó represalias: ratificó el despido de los 33 operarios previos a la protesta y dejó cesante a otros 338 , entre los cuales se incluía toda la comisión interna y el cuerpo de delegados. Además, fueron procesados por el juez penal de San Isidro, Ángel Papalia, todos los miembros de la comisión interna y un delegado del comedor. El 24 de julio, el presidente de Ford Argentina, Robert Sparvero, el Ministro Hugo Barrionuevo y el líder del SMATA, José Rodríguez, firmaron un acuerdo con el cual se daba por cerrado el conflicto. Así lograron aislar a la comisión interna y legitimar la posición de la empresa.

Como respuesta, los obreros decidieron en asamblea realizar una movilización a Plaza de Mayo (el 18 de julio), en la que participaron-según

10. "Cuando los obreros dirigieron la Ford", Hoy, servir al pueblo, No $82,14 / 8 / 1985$, p. 4.

11. "Procesan a trabajadores de Ford", Crónica (1era. edición), 9/7/1985, p. 2. 
las fuentes consultadas- entre 1.000 y 2.000 personas. Luego de la marcha, la comisión interna fue recibida por el Ministro del Interior, Antonio Tróccoli, a quien le entregaron un petitorio que exigía la reincorporación de los obreros despedidos. El Ministro les prometió gestionar una audiencia con Alfonsín que nunca ocurriría. ${ }^{12}$

Quince días después del final de la ocupación, la empresa decidió reiniciar las actividades del complejo de Pacheco luego de supervisar que las instalaciones se encontraban en buen estado. Con vigilancia policial en los alrededores, todos los obreros fueron palpados y revisados por el personal de vigilancia. La directiva del SMATA impuso una nueva comisión interna cuyos miembros intimidaron a los trabajadores para que estuvieran "tranquilos" y no asistiesen a la asamblea convocada en horas de la tarde. En esa asamblea, a la que concurrieron 1.600 trabajadores, se rechazó el acuerdo firmado entre el sindicato, la empresa y el gobierno y, además, se decidió prorrogar el mandato de la comisión interna y el cuerpo de delegados cesanteados. No obstante los intentos de resistencia de los obreros, la empresa continuó con su ofensiva y en los días siguientes a la reapertura del complejo continuaron los despidos que incluyeron aproximadamente 500 trabajadores. ${ }^{13}$

Como ya se ha señalado, la derrota de los obreros de Ford implicó "la eliminación de todo el activismo que participó de la Lista Naranja, generó las condiciones suficientes para que los sectores oficialistas (Lista Verde) se articulen dentro de la planta hasta hacerse de la conducción de la organización gremial en el lugar de trabajo. Los salarios, a partir de 1985, iniciaron un proceso de caída de largo plazo, mientras la empresa continuó con el proceso de reducción del personal, aumentando la intensidad de la explotación de los trabajadores que quedaban en la planta" (Giniger, Guevara, Hernández y Rivero, 2010: 155).

\section{Posiciones frente al conflicto}

A continuación abordamos las estrategias y posturas de los principales actores que participaron a favor y en contra de la toma de la planta automotriz. Comenzamos con las agrupaciones de izquierda que influyeron en la organización de la ocupación del establecimiento y finalizamos con el análisis de la posición de la empresa, la cúpula del SMATA y el Estado.

El PCR-PTP fue la agrupación con mayor presencia e influencia en la ocupación de Ford. Como ya mencionamos, el coordinador de la comisión interna, Miguel Delfini, miembro de la Lista Naranja, era militante de esta agrupación. En los inicios del conflicto, la posición del partido maoísta

12. "Ford: marcha bajo la lluvia", Crónica (1era. edición), 19/7/1985, p. 3.

13. "Clima represivo y 470 despidos más", Hoy, servir al pueblo, núm. 80, 31/7/1985, p. 4. 
consistió en reivindicar los motivos de la ocupación (despidos que implicaban un incumplimiento del acta-acuerdo del 17 de mayo por la empresa), impulsar una organización eficiente de la misma y catalogar de "traidor" a José Rodríguez, líder del SMATA, por condenar esta metodología desde un comienzo. ${ }^{14}$

Esta agrupación consideraba que la ocupación de Ford servía para demostrar que la clase obrera estaba preparada "para oponer su firmeza de clase al guante de terciopelo, a la hipocresía, con la que el alfonsinismo recubre la más descarnada opresión imperialista y oligárquica”. Esperaba que esta toma pudiese representar un avance en la unidad de un bloque de fuerzas capaz de ganar elecciones de noviembre y conquistar "una Asamblea Constituyente Soberana, capaz de instaurar un gobierno patriótico y popular y un plan de emergencia que asegure pan, trabajo, tierra, libertad e independencia nacional". ${ }^{15}$ Este discurso buscaba deslegitimar los consensos en torno al orden democrático liberal comenzado a fines de 1983 y al mismo tiempo reivindicar otro tipo de prácticas de participación articuladas con la lucha contra el imperialismo y la burguesía. En este sentido, el PCR-PTP contrastaba la democracia vigente con la organización asamblearia de los obreros en el lugar de trabajo. Tanto la elección de los miembros de la comisión interna y el cuerpo de delegados como las asambleas masivas realizadas durante la ocupación mostraban métodos que consideraba verdaderamente democráticos. ${ }^{16}$

El maoísmo también hizo hincapié en la puesta en marcha de la planta bajo control obrero realizada el jueves 11 y el viernes 12 de julio. Para este partido, esa acción demostraba que los trabajadores no necesitaban a los patrones para producir y que incluso era más seguro.

El desalojo policial de la planta fue caracterizado como la demostración de que, lejos de ser un punto de quiebre, la democracia representaba la continuidad del régimen militar. Quedaba establecido que el gobierno de Alfonsín y el Poder Judicial no desempeñaron un rol neutral, sino que fueron funcionales a los intereses de Ford. En este sentido, luego del desalojo, Delfini realizó una declaración pública en la cual catalogaba al presidente como el "general Alfonsín" y señaló que con este hecho el "Proceso" no había "muerto". 17

Si bien durante el conflicto no pudimos vislumbrar divisiones entre las

14. "Los protagonistas son los 4.800 obreros de Ford", Hoy, servir al pueblo, $\mathrm{N}^{\circ} 76$, 3/7/1985, pp. 6-7.

15. Ricardo Fierro, "Todos o ninguno. Después de Ford, nada volverá a ser igual para las masas", Hoy, servir al pueblo, N 77, 10/7/1985, p. 12.

16. Ricardo Fierro, "El general Alfonsín”, Hoy, servir al pueblo, No 78, 17/7/1985, p. 12 .

17. “El Proceso Militar no ha muerto", Hoy, servir al pueblo, No 78, 17/7/1985, p. 3. 
diferentes agrupaciones de izquierda que estuvieron dirigiendo o apoyando la toma de la planta, al finalizar la ocupación observamos que surgieron críticas y recriminaciones entre las mismas. En estas discusiones afloraban disputas que tenían que ver con enfrentamientos ideológicos y con las internas político-sindicales de la coyuntura.

Para el PCR-PTP, el final de la ocupación y los posteriores despidos de los trabajadores no debían ser tomados como una derrota del movimiento obrero, un punto de vista contrario al resto de las agrupaciones que participaron del conflicto. Para los maoístas, significaba una batalla perdida dentro de una guerra que continuaba. En este sentido, afirmaba que lo acontecido en la planta de Ford "ayudó a millones a comprender la esencia antiobrera y antinacional del 'plan alfonsinista', y del contubernio gobierno-Estadopatronal-jerarcas en que se apoya". ${ }^{18}$ Quedaba establecido, entonces, que para esta agrupación los principales culpables del desenlace que tuvo la ocupación fueron -en igual medida- la empresa, el gobierno de Alfonsín y la cúpula del SMATA.

El PC -que no formaba parte de la Lista Naranja- criticó este equiparamiento de responsabilidades. Al contrario del resto de las agrupaciones de izquierda, los comunistas señalaban que, si bien la conducción del SMATA no accionó durante el conflicto, José Rodríguez no debía ser considerado un "traidor". Reconocían su participación activa en el acuerdo del 24 de julio entre la dirección de la dirección sindical, el gobierno y la empresa, aunque desde esta postura el principal enemigo era el imperialismo, que a través del Fondo Monetario Internacional (FMI) y la empresa impuso condiciones al gobierno. Como señalaban militantes comunistas de la fábrica, lo que había que lograr, mediante la movilización, era que el SMATA y la CGT se pusiesen al frente de la lucha. ${ }^{19}$

También el PC fue crítico de la conducción que tuvo la ocupación de Ford, acusando al maoísmo de llamar a la desafiliación e impulsar la creación de un sindicato paralelo durante la asamblea realizada del 29 de julio tras la reapertura de la planta de General Pacheco. ${ }^{20}$ Esto último fue desmentido tajantemente por el PCR-PTP, señalando que Delfini en esa asamblea había anunciado que toda la comisión interna renunciaría en bloque si los obreros reunidos allí decidían la desafiliación. Para esta agrupación, el PC era parte de una campaña orquestada junto a la cúpula sindical y el gobierno con el fin de "confundir a las masas". ${ }^{21}$

18. Ricardo Fierro, "El general Alfonsín”, op. cit., p. 12.

19. "Que no aíslen la lucha en Ford", Qué pasa, No 229, 24/7/1985, p. 3; "Cuidar la unidad", ídem, pp. 8-9.

20. "Ford: sigue el combate", Qué pasa, N² 230, 31/7/1985, p. 7.

21. "Campaña Alfonsín-Rodríguez-P'C", Hoy, servir al pueblo, No 81, 7/8/1985, p. 8 . 
Además del maoísmo, las agrupaciones trotskistas MAS y PO también formaban parte de la Lista Naranja que dirigió la toma en Ford. A diferencia del PCR-PTP, el MAS consideró que el final de la ocupación fue un paso atrás para los obreros ya que quedaban "en peores condiciones que antes. Tuvieron que abandonar la fábrica sin nada a cambio”. En contraposición con el PC, evaluó que los principales responsables del fracaso de la lucha en la planta de General Pacheco habían sido los directivos del SMATAjunto con los líderes de la CGT. Esta agrupación también condenó la inacción del Partido Intransigente y el PJ. Señalaba que el diputado peronista Imbelloni y Herminio Iglesias -quienes tenían vínculos con algunos trabajadores de la planta- "desaparecieron en los momentos decisivos, la noche del sábado [13 de julio] cuando el gobierno ordenó la represión” ${ }^{22}$

De igual forma realizó críticas a la comisión interna debido a que en la asamblea general del día posterior al desalojo "no aprovechó la presencia de tantos compañeros para comenzar a organizar toda la base para la posibilidad de una lucha afuera de la fábrica. Comisiones por barrio y un boletín informativo son dos de las herramientas organizativos indispensables para esta situación”. ${ }^{23} \mathrm{El}$ MAS planteaba, así, que hacía falta extender la lucha más allá de los límites de la planta, buscando recuperar metodologías utilizadas por los trabajadores en los años previos a la última dictadura militar. Una segunda objeción a la comisión interna consistió en que una parte de ella impuso que un abogado ligado a las 62 Organizaciones tomase la defensa de los procesados, dejando afuera del litigio a letrados de otras agrupaciones. La primera de estas críticas quizás estaba dirigida de forma indirecta hacia el PCR-PTP que dio apoyo a la postura tomada por la comisión durante esa asamblea. ${ }^{24} \mathrm{Y}$ la segunda impugnación probablemente tuvo como destinatario al sector ligado a la Lista Azul y Blanca con vínculos con las 62 Organizaciones.

La otra agrupación trotskista presente en Ford, el PO, coincidía con el MAS y el PCR-PTP en señalar que desde el inicio de la toma el gobierno de Alfonsín, la patronal y la burocracia sindical del SMATA habían actuado al unísono. Agregaba que era la cúpula gremial la que había "tomado la voz cantante en la campaña para aplastar el conflicto". ${ }^{25}$

Luego del desalojo de la planta, este partido planteaba como estrategia a seguir la ocupación de la Panamericana (la ruta principal de la Zona Norte) como forma más efectiva de lograr "la mayor movilización de los

22. "Ford: después de 19 días de ocupación", Solidaridad Socialista, No 113 , $18 / 7 / 1985$, p. 9.

23. Ídem.

24. Véase: "Asamblea masiva en Ford", Hoy, servir al pueblo, No 78, 17/7/1985, p. 12 .

25. "Directo desde Ford", Prensa Obrera, N 103, 27/6/1985. 
trabajadores y de ese cordón de solidaridad obrera y barrial que desfiló por la puerta 2". ${ }^{26}$ Esta posición no tuvo la respuesta esperada por el PO ya que los obreros de Ford decidieron, en su lugar, marchar a Plaza de Mayo como proponía el PCR-PTP.

También difería con la agrupación maoísta en cuanto evaluaba que la lucha había terminado en derrota. Como balance establecía que, frente al bloque común del gobierno, la burguesía, el imperialismo, el Poder Judicial y la burocracia sindical, tendría que haber existido una mayor preparación por parte de los obreros frente a la cesantía. Principalmente, la gran lección que dejaba el conflicto para este partido era la necesidad de buscar solidaridad en fábricas y barriadas vecinas. En este sentido, el PO criticaba a la comisión interna y al cuerpo de delegados por haber puesto expectativas en el juez Ángel Papalia que manejaba una de las causas penales abiertas durante el conflicto (al que algunos obreros denominaban "el juez bueno"), en la mediación parlamentaria y en las supuestas propuestas del Ministerio de Trabajo. Esta falsa ilusión habría bloqueado la iniciativa del PO de ocupar la Panamericana que también proponían comisiones internas de fábricas aledañas. ${ }^{27}$

Además, sostenía que tampoco se tendría que haber esperado nada de la Iglesia Católica, del SMATA ni de la CGT, que pretendieron "desangrar el movimiento de lucha, lograr luego alguna reincorporación y dejar en la calle a los compañeros más luchadores". ${ }^{28}$ Esto pareció confirmarse cuando la conducción del sindicato, el gobierno y los directivos de Ford firmaron el acuerdo del 24 de julio que legitimaba la posición de la empresa, en el cual la Pastoral Social de la Iglesia Católica acercó posiciones.

Como ya mencionamos, este acuerdo fue el último eslabón de la estrategia de la cúpula gremial para impulsar la expulsión de los activistas de izquierda de la empresa e intentar negociar la cantidad de despidos y suspensiones. Desde un principio, el consejo directivo nacional del SMATA condenó la ocupación de la planta. Ante el Ministerio de Trabajo, Rodríguez señaló que la medida de fuerza no había sido autorizada ni propiciada por el sindicato y que estaba orquestada por la Lista Naranja. También declaró que "en épocas de crisis no podemos hacernos los revolucionarios. Tenemos que ir a negociar con inteligencia". ${ }^{29}$ Aunque argumentaba que Ford buscó deliberadamente provocar a los operarios con los despidos, afirmaba que el

26. Partido Obrero Zona Norte, "Ocupemos la Panamericana", 24/7/1985. Citado en Prensa Obrera, No 106, 25/7/1985, p. 4.

27. "Nuestro aporte a un balance de la lucha de Ford", Prensa Obrera, N ${ }^{\circ} 106$, 25/7/1985, p. 5.

28. Partido Obrero Zona Norte, “Ocupemos la Panamericana”, op. cit., p. 4.

29. Declaración citada en "Hay dos caminos", Solidaridad Socialista, N ${ }^{\circ} 113$, $18 / 7 / 1985$, p. 2. 
SMATA no avaló la toma de la fábrica y que la misma había sido impulsada por militantes del PCR-PTP que habían obtenido "el 4\% de los votos en las elecciones internas" ${ }^{30}$ Omitía que en Ford la Lista Naranja había logrado más votos $(40 \%)$ que la Lista Verde oficialista $(7,9 \%)$ en esas elecciones. De esta manera, por un lado, Rodríguez buscaba evitar que el gobierno cumpliese la amenaza de quitarle la personería gremial del SMATA y lo inhabilitase por tres años para conducir el sindicato y, por otro, deslegitimar a los activistas de izquierda que impulsaban la medida de fuerza. ${ }^{31}$

Cuando la toma estaba por llegar a su fin, la dirección del sindicato denunció la existencia de un pacto entre la comisión interna y la Ford. Daba a entender que la empresa buscaba parar la producción y justificar nuevos despidos, mientras que la organización de base utilizaba el conflicto para posicionarse políticamente al interior del sindicato. ${ }^{32}$ Tras el final de la ocupación y la imposición de una nueva comisión interna por la conducción sindical, fueron cesanteados obreros que, en su mayoría, eran activistas de la Lista Naranja. Esto provocaría una merma sustancial en la influencia de las agrupaciones de izquierda dentro de la planta.

Mientras la dirección del gremio no avalaba la medida de fuerza y era funcional a la empresa, esta última trazó una posición pública que consistió, principalmente, en justificar los despidos efectuados al comienzo del conflicto y condenar la ocupación de la fábrica como un ataque a la propiedad privada. Además, se negó a reunirse con los miembros de la comisión interna y el cuerpo de delegados mientras se mantuviese la ocupación.

En este sentido, la puesta en funcionamiento del complejo industrial por los operarios también fue duramente criticada por Ford. En un documento señalaba que esta acción implicaba "nuevas violaciones al derecho de propiedad" y que se ponían en riesgo los equipos y maquinarias, ya que faltaba supervisión y asistencia técnica. ${ }^{33}$

Como herramienta fundamental en la construcción de legitimación de su postura apeló a la lógica del régimen democrático. Acusaba a la comisión interna de violar normas vigentes -principalmente el ataque a la propiedad privada-, no haber realizado gestiones de reclamos con los representantes de la empresa, el sindicato o el Ministerio de Trabajo, y por haber detenido en las instalaciones a personal administrativo una vez comenzada la ocupación. Concluía postulando que "el país entero reclamó y ha aceptado el imperio de

30. "Buscaron deliberadamente el conflicto"' y "José Rodríguez: 'SMATA no avala' toma de la fábrica” (artículos sin firma), Crónica (1era edición), 28/6/1985, p. 3.

31. Luis Majul, “¿Contraofensiva en julio?”, El periodista de Buenos Aires, N 43, 5/7 al $11 / 7 / 1985$, p. 9.

32. "Grave imputación de SMATA: un pacto", Crónica (1era. edición), 14/7/1985, p. 3.

33. "Advertencia empresaria", Crónica (1era edición), 11/7/1985, p. 2. 
la ley, sea pues la ley la que determine las responsabilidades y derechos de cada una de las partes en la presente situación". ${ }^{34}$ De esta forma la empresa intentaba articular la defensa de su propiedad privada y la deslegitimación del accionar de la comisión interna con los consensos sociales a favor de la reapertura democrática para consolidar su postura. ${ }^{35}$

El gobierno actuó eficazmente en esta deslegitimación de la medida de fuerza de los trabajadores desde la lógica del Estado de Derecho. Para la administración Alfonsín la ola de tomas, paros parciales, reclamos y movilizaciones por parte del movimiento obrero representaban una amenaza al plan económico lanzado en junio. Por un lado, necesitaba subyugar a los trabajadores para establecer un consenso con los llamados "capitanes de la industria" y el sector financiero. Por otro, este disciplinamiento debía estar enmascarado con herramientas legales para no romper la ilusión democrática impulsada por el alfonsinismo, que presentaba al gobierno como la antítesis de la última dictadura militar.

Durante la toma puede observarse esta estrategia a través de las declaraciones en los días previos al desalojo. Desde un primer momento, declaró ilegal la ocupación de la fábrica Ford porque -como señalaba el Secretario General de la Presidencia, Germán López- el gobierno debía "garantizar la vigencia del orden constitucional, donde la propiedad privada es una de sus piedras basales" ${ }^{36}$ Incluso se justificaba el procesamiento de los líderes de la toma en Ford ya que, en palabras del Ministro del Interior Tróccoli, la medida representaba una "violación del sistema jurídico" y que por ello estaba incorporado al código penal. En la misma dirección se alineaba el bloque de la UCR en el Poder Legislativo. El presidente de la Cámara de Diputados, el radical Juan Carlos Pugliese, calificaba la ocupación como un "acto delictual". ${ }^{37}$

Paralelamente a estas declaraciones, el Ministerio de Trabajo mantuvo reuniones con la comisión interna y el cuerpo de delegados mientras duró la ocupación. Al no poder conseguir una salida que satisficiera tanto a los trabajadores como a los representantes de la empresa, se limitó a realizar promesas a los obreros en conflicto que, en la práctica, eran irrealizables. El principal ejemplo de esto último puede observarse horas antes del desalojo

34. "Por qué Ford no se va", op. cit., p. 11.

35. "UIA: 'se lesiona a la democracia", Clarin, 3/7/1985, p. 3. Cabe aclarar que el titular de la UIA era Roberto Favelevic, quien encabezaba el Movimiento Industrial Argentino que representaba a los sectores más concentrados de la burguesía y del que formaba parte la empresa Ford. Este nucleamiento había dado apoyo al Plan Austral desde sus inicios (Aruguete, 2006: 443).

36. Tabaré Áreas, "El plan amenazado", op. cit., p. 11.

37. "Tróccoli: Acto de fuerza que viola sistema jurídico" y "Pugliese: "la toma, un acto delictual" (artículos sin firma), Crónica (1era. edición), 13/7/1985, p. 3. 
cuando el Ministro de Trabajo comunicó a los representantes obreros que los 33 trabajadores despedidos en el inicio del conflicto serían reincorporados y, posteriormente, esos despidos serían revisados entre la empresa y la comisión interna. Horas después esta propuesta fue modificada sustancialmente por el Ministerio impidiendo el acuerdo y generando confusión en los trabajadores que permanecían en la planta.

Finalmente, ese mismo día Alfonsín condenó la ocupación declarando: "No existe ningún país en el mundo bajo cualquier sistema político que tolere este tipo de ocupación, por lo que nosotros tenemos que recurrir a la Justicia y actuar de acuerdo con la ley" ${ }^{38}$ La crítica tenía como objetivo legitimar el accionar represivo estatal contra los trabajadores poniéndolos por fuera de los límites de lo que el régimen democrático podía tolerar.

En este sentido, estos argumentos contra los obreros de Ford se hacían desde el enmascaramiento legal, lo cual era funcional al interés del gobierno para mostrarse como defensor del orden constitucional. Por esta razón, el Poder Judicial fue el encargado de llevar a cabo la represión legal contra los trabajadores. Mientras que el juez federal Carlos Valdez se ocupó de dirigir el operativo policial para desalojar la planta, el juez penal de San Isidro Ángel Papalia fue quien se encargó de procesar y dictar prisión preventiva para toda la comisión interna (aunque luego serían eximidos de esta última) por "privación ilegítima de la libertad calificada, turbación de la posesión, daños, hurtos reiterados, uso ilegítimo de automotores, lesiones leves y usurpación de propiedad". ${ }^{39}$

Como vimos, en los días siguientes al desalojo el Ministerio de Trabajo se encargó de legitimar la posición de la empresa pactando con la cúpula del SMATA y los directivos de Ford. La democracia del Nunca más se transformaba, así, en la principal garante de la derrota de los obreros de Ford.

\section{Reflexiones finales}

Para finalizar, proponemos una serie de reflexiones que pueden ser útiles para análisis e investigaciones posteriores sobre la conflictividad social de este período. En primer lugar, señalamos que durante la ocupación de Ford, los partidos de izquierda que formaban parte de la Lista Naranja que dirigió la toma mantuvieron una posición en común o al menos no parecieron mostrar divergencias públicamente. Luego del desalojo, salieron a la luz acusaciones recíprocas, principalmente sobre el resultado del conflicto, acerca del grado de responsabilidades del Estado, la empresa y la dirigencia sindical y en

38. “Nadie puede tolerar la ocupación de la Ford', dijo Alfonsin”, Clarín, 14/7/1985, pp. 4,5 .

39. "Los obreros de Ford resistirán el desalojo", Crónica (5ta. edición), 2/7/1985, p. 8. 
cuanto a las fallas en la organización y los pasos a seguir. Sin embargo, estas diferencias no alcanzan para explicar la derrota obrera en Ford.

El análisis sobre las causas del desenlace que tuvo la lucha en Ford deben centrarse en el poder acumulado por la burguesía a partir de los cambios estructurales en el capitalismo y por la masacre estatal de los años 70, y no necesariamente en la incapacidad estratégica de la izquierda argentina, también golpeada por el accionar represivo en los años previos. Igualmente, se vuelve necesario realizar investigaciones en torno a la magnitud cuantitativa y cualitativa, el anclaje y estrategias de las agrupaciones de izquierda en el movimiento obrero durante los principios de la llamada transición democrática.

Una segunda reflexión que se desprende consiste en considerar que el conflicto en Ford evidenció que las diferencias entre los nucleamientos peronistas sindicales no eran sustanciales. La Comisión Nacional de los 25 -de la que el SMATA formaba parte- se presentaba a sí misma como una corriente combativa y democrática dentro del movimiento obrero en oposición a la burocracia conducida por Lorenzo Miguel, quien controlaba las 62 Organizaciones. No obstante, puede decirse que el rol cumplido por la conducción nacional del gremio mecánico durante la toma de Ford demostró que estos líderes sindicales no representaban un verdadero intento de cambio de las prácticas sindicales. Por el contrario, el conflicto exhibió que estas divisiones entre los nucleamientos formaban parte de internas políticas dentro de la burocracia sindical.

En tercer lugar, los activistas de la Ford remitieron a estrategias de resistencia y enfrentamiento presentes en los años previos a la dictadura militar, en los cuales la comisión interna y el cuerpo de delegados de la empresa habían tenido una participación destacada en la Coordinadora Interfabril de la Zona Norte (Giniger, Guevara, Hernández y Rivero, 2010: 148-149; Löbbe, 2006). Como ya mencionamos, la imposibilidad de recomponer estas experiencias se relaciona, principalmente, con la crisis económica que atravesaba el país, la situación recesiva de algunas ramas industriales y las consecuencias provocadas por el exterminio estatal llevado a cabo en los años previos a la reapertura democrática. En este sentido, el momento de mayor represión contra el movimiento obrero por parte del Estado y la burguesía ocurrió durante la segunda mitad de la década de 1970. Ahora bien, uno de nuestros objetivos en este trabajo fue intentar mostrar que durante el período constitucional la represión estatal continuó en funcionamiento pero con otra modalidad legitimada desde la lógica del Estado de Derecho. Sostenemos que para comprender el éxito del Estado en esta tarea, en gran parte, debemos examinar la construcción de consensos hegemónicos en torno a los principios de la democracia constitucional. Dentro de estos valores se incluía la reprobación de las metodologías utilizadas por los trabajadores en conflictos sociales de los años 70. Como ya mencionamos, durante la coyuntura en que 
enmarcamos esta investigación, el Estado, principalmente a través de la “teoría de los dos demonios", buscó no sólo condenar el accionar represivo llevado a cabo por las Fuerzas Armadas en los años previos a la reapertura constitucional, sino también "demonizar" las luchas de las fracciones más radicalizadas de la clase obrera. En los primeros años de la transición democrática la utilización de esta representación del pasado resultaba funcional a la burguesía y al Estado para deslegitimar las luchas sindicales como la llevada a cabo por los trabajadores de la planta de Ford.

Pensamos que durante el conflicto analizado en este trabajo existieron indicios que pueden dar cuenta de esta construcción exitosa de consensos. La empresa se amparó en la democracia y en la legalidad para justificar su posición. La defensa de la propiedad privada y del derecho a despido del personal (incluso de los primeros 33 operarios expulsados de la fábrica que incumplía el acuerdo del 17 de mayo) fueron elementos presentes en el discurso con el que la cúpula de Ford justificó su ataque contra la comisión interna y el cuerpo de delegados. El gobierno alfonsinista también legitimó el desalojo de la planta caracterizando la toma como un acto delictivo por fuera de los límites del régimen democrático. Esta concepción hacía posible, entonces, que el Poder Judicial pudiese autorizar el desalojo a manos de la fuerza policial.

No obstante, puede objetarse que la postura de los actores de la burguesía y el Estado no alcanza para explicar la efectividad de la construcción de consensos sociales amplios en torno a la democracia y la condena de este tipo de medidas de fuerza. Por esa razón, resulta interesante intentar dar cuenta de cuáles fueron las reacciones de los obreros involucrados en la toma y de otros sectores sociales subalternos. En este sentido, cabe reseñar la crítica que realizó el PO hacia la comisión interna y el cuerpo de delegados en el final de la ocupación por haber confiado en las promesas realizadas por el Ministerio de Trabajo, representantes parlamentarios, la Iglesia Católica y uno de los jueces que acudían a la planta durante la toma para supuestamente solucionar el conflicto. Esta crítica nos puede indicar que, probablemente, muchos trabajadores creían que el Estado de Derecho podía respaldar su posición. Esto implicaría reproducir la noción de que las instituciones estatales en democracia defendían los intereses de toda la ciudadanía por encima de los intereses corporativos. Esta perspectiva los conduciría a confiar en que representantes parlamentarios o funcionarios judiciales se podían poner del lado de la clase obrera en lugar de ser funcionales a los sectores más concentrados del capital. No obstante, esta reflexión debe ser respaldada con una investigación más amplia que podría incluir, por ejemplo, el registro de las experiencias de la ocupación de Ford a través de fuentes orales.

Si bien existieron adhesiones formales a la ocupación de la planta de General Pacheco de dirigentes de agrupaciones políticas opositoras al 
gobierno, artistas, comisiones internas de otras empresas, centros de estudiantes y miembros de organizaciones de derechos humanos, lo cierto es que en el momento del desalojo y en la posterior ofensiva de la empresa los trabajadores de Ford quedaron aislados. Faltaron apoyos activos que permitiesen construir una fuerza social que pudiese resistir la embestida de la empresa y el Estado contra los trabajadores. Una vez más cabe aclarar que las condiciones económicas y políticas generales hacían muy difícil esta construcción. Pero, además, resulta pertinente reproducir lo que en esta coyuntura señalaba un conocido analista político vinculado a los sectores más concentrados de la burguesía:

Si se excluye el comportamiento de figuras irremediablemente comprometidas con la ultraizquierda como Zamora, Hebe de Bonafini y Pérez Esquivel, y con la excepción de un exabrupto de Saúl Ubaldini, ningún sector político, estudiantil o gremial se movilizó en apoyo de los ocupantes. [...] Otras figuras y sectores, como la izquierda estudiantil, el propio Alende $\mathrm{y}$, por supuesto, la dirección nacional de SMATA, callaron o criticaron con motivo de la ocupación. [...] ¿Qué ha pasado para que la inmensa mayoria de los argentinos, hoy, se niegue a acompañar lo que hace poco auspiciaba activa o pasivamente? Algo tan sencillo como maravilloso: el aprendizaje. [...] Duras lecciones fueron necesarias para ello, pero al cabo de golpes de Estado, violencia subversiva, represión indiscriminada y el consiguiente proceso de decadencia al fin aprendimos que el camino es otro: la juridicidad. [...] Delfini llevó a sus compañeros, entonces, a la reiteración de actitudes que han sido condenadas por la sociedad. Actuó contra los nuevos valores vigentes. [...] La sociedad miró para otro lado. ${ }^{40}$

Más allá de su caracterización acerca de los actores que adhirieron a la causa de los obreros y sobre el fracaso de la ocupación que consideraba positiva -producto de su concepción liberal-, nos interesa remarcar la apreciación acerca de la falta de apoyos. Desde este punto de vista, muchos de los sectores que habían aprobado medidas de fuerza llevadas a cabo por organizaciones de base en los años 70, luego de la reapertura democrática trocaron hacia una postura contraria a estas metodologías de lucha. Tomando como válida esta afirmación, el "aprendizaje" logrado por la sociedad puede ser considerado como consecuencia no sólo de la represión estatal, sino también por la exitosa construcción de consensos hegemónicos a partir de la "demonización" de las luchas llevadas a cabo por la clase obrera y otros sectores subalternos en las décadas previas a la restauración de la democracia. En este sentido,

40. Mariano Grondona, "Los dos pueblos", Somos, No 461, 19/7/1985, p. 20. 
las tomas de fábricas en defensa de las condiciones de existencia de la clase obrera no estaban dentro de los "nuevos valores" reproducidos por sectores sociales que aceptaban la "ilusión democrática" impulsada por el Estado de Derecho. Esta afirmación también necesita ser profundizada a través de futuros trabajos que se propongan comparar los consensos, críticas y apoyos sociales a los conflictos que existieron entre las décadas del 70 y 80 .

En conclusión, somos conscientes de que se vuelve necesario profundizar el análisis sobre la lucha entre capital y trabajo en este período. Probablemente, así podamos colaborar con el desenmascaramiento de consensos legitimadores construidos por el Estado de Derecho que han sido, y siguen siendo, funcionales a los intereses de la clase dominante.

\section{Bibliografia}

Aruguete, Eugenia (2006), "Lucha política y conflicto de clases en la posdictadura. Límites a la constitución de alianzas policlasistas durante la administración Alfonsín", en Alfredo Pucciarelli (coord.), Los años de Alfonsín. ¿El poder de la democracia o la democracia del poder?, Buenos Aires: Siglo XXI, pp. 413-457.

Aspiazu, Daniel, Eduardo Basualdo y Miguel Khavisse (2004), El nuevo poder económico en la Argentina de los años ochenta. Edición definitiva, Buenos Aires: Siglo XXI.

Belardinelli, Pablo (1994), "El marco político de la conflictividad obrera", en Ernesto Villanueva (coord.), Conflicto obrero. Transición política, conflictividad obrera y comportamiento sindical en la Argentina, 1984-1989, Buenos Aires: Universidad Nacional de Quilmes, pp. 103-149.

Bonanotte, César y Norberto Zeller (1994), "Las causas de los conflictos", en Ernesto Villanueva (coord.), Conflicto obrero. Transición política, conflictividad obrera y comportamiento sindical en la Argentina 1984-1989, Buenos Aires: Universidad Nacional de Quilmes, pp. 83-93.

Campione, Daniel (2007), "Desde Gramsci hacia una nueva época", en Daniel Campione, Para leer a Gramsci, Buenos Aires: Ediciones del Centro Cultural de la Cooperación Floreal Gorini, pp. 135-181.

Crenzel, Emilio (2008), La historia politica del Nunca Más, Buenos Aires: Siglo XXI.

García Allegrone, Verónica, Florencia Partenio y María Inés Fernández Álvarez (2003), "Ocupaciones fabriles: un rastro en las experiencias históricas", VI Congreso Nacional de Estudios del Trabajo: "Los trabajadores y el trabajo en la crisis", Buenos Aires. Disponible en: http:/ /www.aset. org.ar/congresos/6/archivosPDF/grupoTematico03/006.pdf (última fecha de ingreso: 29-6-2012).

Giniger, Nuria, Sebastián Guevara, Marcelo Hernández y Cynthia Rivero (2010), "Las huellas del terrorismo de Estado sobre el movimiento obrero. Los casos de Ford y Acindar", en Claudia Figari, Paula Lenguita y Juan 
Montes Cató (comps.), El movimiento obrero en disputa. La organización colectiva de trabajadores, su lucha y resistencia en la Argentina del siglo XX, Buenos Aires: Ediciones Ciccus, pp. 143-162.

Gramsci, Antonio (1999), Cuadernos de la cárcel, tomo V, edición crítica del Instituto Gramsci a cargo de Valentino Gerratana, México DF: Ediciones Era-Benemérita Universidad Autónoma de Puebla.

Hernández, Víctor (1985), "La ocupación de fábrica como forma de lucha obrera. El caso de Ford Motors Argentina", Cuaderno CICSO, Serie Estudios $\mathrm{N}^{\circ} 62$.

Löbbe, Héctor (2006), La guerrilla fabril. Clase obrera e izquierda en la Coordinadora de Zona Norte del Gran Buenos Aires (1975-1976), Buenos Aires: Ediciones RyR.

Novaro, Marcos (2009), Argentina en el fin de siglo. Democracia, mercado y nación (1983-2001), Buenos Aires: Paidós.

Ortíz, Ricardo y Martín Shorr (2006), "La economía política del gobierno de Alfonsín: creciente subordinación al poder económico durante la 'década perdida”, en Alfredo Pucciarelli (coord.), Los años de Alfonsín. ¿El poder de la democracia o la democracia del poder?, Buenos Aires: Siglo XXI, pp. 291-333.

Palomino, Héctor (2005), "Los cambios en el mundo de trabajo y los dilemas sindicales", en Juan Suriano (dir.), Dictadura y democracia (1976-2001), tomo X de Nueva Historia Argentina, Buenos Aires: Sudamericana, pp. 377-442.

Pozzi, Pablo y Alejandro Schneider (1994), "Combatiendo al capital". Crisis y recomposición de la clase obrera argentina (1982-1992), Buenos Aires: El Bloque Editorial.

Santella, Agustín (2008), Trabajadores, sindicato y conflictos en la industria automotriz. Un estudio de caso (1989-2006), tesis de doctorado, Buenos Aires: Universidad de Buenos Aires.

$$
* * *
$$

Resumen: El artículo encara el caso de la ocupación obrera de la planta Ford de General Pacheco ocurrida entre el 26 de junio y el 14 de julio de 1985 . Su relevancia no sólo deriva de la masividad de los acontecimientos -más de 3.800 obreros participaron de la toma- sino, también, de la trascendencia pública y el impacto que provocó en los principales actores políticos del momento. En el desarrollo del texto examinamos, por un lado, la organización obrera, dando cuenta del rol de las corrientes políticas involucradas en el conflicto, y, por el otro, las estrategias patronales y estatales frente al mismo. Por último, reflexionamos sobre la relación existente entre la construcción de legitimidad del orden democrático naciente y el silenciamiento de ciertas prácticas gremiales de base de larga data en el sindicalismo argentino.

Palabras clave: toma de fábrica - gobierno de Alfonsín - movimiento obrero partidos de izquierda 


\begin{abstract}
The article presents a case study of the occupation of the Ford factory by its own workers that took place between June 26th and July 14th, 1985, in General Pacheco, Buenos Aires. Its importance derives not only from the massiveness of the event -over 3800 workers participated in the occupation- but also from the public importance and the impact it had among the main political actors of the time. On the one hand, the paper examines the features of labor organization, assessing the role played by the political parties involved in the conflict. On the other hand, it examines the strategies developed by the employers and the state against the workers. Finally, it assesses the relationship between the construction of legitimacy of the nascent democratic order and the silencing of certain rank-and-file practices that show a long-standing tradition in Argentine unionism.
\end{abstract}

Keywords: factory occupation - Alfonsín government - workers movemento - leftist parties

Recepción: 28 de febrero de 2013. Aprobación: 20 de marzo de 2013. 